PRACTICAL MEASURING TECHNIQUES FOR BETA RADIATION 
PHILIPS TECHNICAL LIBRARY

\title{
Practical Measuring Techniques for Beta Radiation
}

\author{
by \\ L. A. J. VENVERLOO
}

Macmillan Education 
ISBN 978-1-349-01317-3

ISBN 978-1-349-01315-9 (eBook)

DOI 10.1007/978-1-349-01315-9

English edition (C) Philips' Gloeilampenfabrieken, Eindhoven, 1971

Softcover reprint of the hardcover 1st edition 1971 978-0-333-13145-9

All rights reserved. No part of this publication

may be reproduced or transmitted in any form

or by any means, without permission.

SBN 333131452

First published in English by

THE MACMILLAN PRESS LTD

London and Basingstoke

Associated companies in New York, Toronto, Melbourne,

Dublin, Johannesburg and Madras

PHILIPS

(2)

Trademarks of N.V. Philips' Gloeilampenfabrieken 


\section{Contents}

Introduction

Page

vii

Chapter

1 Ionizing Radiation

Atoms-Stable and unstable nuclei-The equivalence of matter and energy - The laws of radioactive decay-Radioactive mixtures-The unit of activity-Specific activityNatural and artificial activity

2 Types of Radiation and their Properties

Beta radiation-Properties of beta radiation-Alpha radiation-Gamma radiation-Decay schemes-Other types of ionizing radiation

3 Radiation Detectors

Gas-filled detectors-The scintillation detector-Semiconductor detectors

\section{Radiation Measuring Equipment}

Pulse-handling equipment-The detector supply voltage-

Amplification and pulse shaping-Analysing sectionPulse-height discrimination-Coincidence and anti-coincidence-Counters-Time measurements-Count-rate meters

5 Measurement and Measurement Errors

Absolute measurements-Comparative measurementsMeasurement errors-The detection limit-Choice of the optimum detector and measuring method

6 The Measurement of Solid and Liquid Samples with End-window Detectors

Absorption-Back-scattering in the sample planchet-

Choice of the detector-Measurements on mixtures-High or low activity; high or low energy-Preparation of the sample-Calibration of the detector-Radiochromatography-Advantages and disadvantages of measurements on solid samples 


\section{Chapter}

\section{Measurements with Liquid Scintillators}

Detectors with liquid scintillators-Solvents and scintil- 104 lators-Quenching-The composition of the scintillatorChoice of the window setting-Measurements on isotopes other than ${ }^{3} \mathrm{H}$ and ${ }^{14} \mathrm{C}$-Calibration methods-Liquid chromatography

\section{Measurements on Gaseous Samples}

Proportional detectors-The efficiency-Counting characteristics-Adjusting the measuring equipment before useThe counting gas-Comparison of the internal gas-filled detector and liquid scintillators-Radio gas-chromatography -Conclusion

References

Appendices

Index 


\section{Introduction}

Radioactive tracers are being used for more and more different applications and by more and more people in recent years. The great interest in tracers is largely due to the high sensitivity, selectivity and accuracy which this new analytical tool manifests over a very wide field.

Most of the people who want to use tracers in their work do not have the time to make a deep study of nucleonics or the theory of the measurement of ionizing radiation; they merely want to know enough to use this tool properly. It is for such people that this book has been written. In it, the various measuring methods, types of equipment and sources of error are discussed and compared so as to give a clear understanding of the properties of the equipment used, which is sure to lead to better use of that equipment.

An extensive reference list is provided for those who would like to read further.

The first two chapters refresh the reader's memory of a number of basic concepts in nuclear physics, in particular with reference to beta radiation.

Radiation detectors are discussed in chapter 3 , and the ancillary measuring equipment in chapter 4. All instruments in common use for beta radiation are discussed here, and all details needed for a thorough knowledge of their operation are mentioned.

The following chapter gives a survey of the various sources of error in the measured results, and how the magnitude of these errors can be estimated. Most attention is paid to those errors which are due to the random nature of the process of radioactive decay.

The last three chapters deal in turn with the three main types of measurements, the distinction between which is based largely on differences in the state of the sample being measured, namely:

- solid or powdered samples, for which end-window beta detectors are generally used;

-liquid samples, where the main topic of discussion is the very widely used detectors for use with liquid scintillators; 
viii PRACTICAL MEASURING TECHNIQUES FOR BETA RADIATION

-gaseous samples, which are generally introduced into a special detector, thus allowing a very high sensitivity to be achieved.

The different measuring methods are discussed in such a way as to bring out the pros and cons of the different methods. This book is therefore also invaluable for the reader who has to make a choice between different measuring systems, e.g. for the equipment of a new laboratory. 